\title{
For Value or for Worth? Part 2: A Neuroeconomical Thought-Action-Mood-Space Modulated by (Un-)Certainty as Sign- or Goal-tracking
}

\author{
Gottfried Reinhold Sebastian Treviranus \\ BipoSuisse, Independent Research, Vereinsweg 11, CH-3012 Berne, Switzerland \\ *Corresponding Author: biposuisse@bluewin.ch
}

Copyright $\bigcirc 2017$ by authors, all rights reserved. Authors agree that this article remains permanently open access under the terms of the Creative Commons Attribution License 4.0 International License

\begin{abstract}
Epistemiology requires trans-disciplinary logics for convergence. Here a logico-geometrically expanded cyclical version of the classical French temperamental and anxio-affective thought-action-moodmodel, " $d y n 4-\mathbf{T A M - c u b e " , ~ h a r b o r i n g ~ A p p r o p r i a t i o n ~ W a v e s ~}$ (AWs), encounters an effort-related node of present neuro-economical debates: the cyclical relation between "value" and "worth". Accordingly, as a fundamental of the brain, this essay's second part continues to explore the alternation between symbolic frontal 4-dimensional (Halford) processing ("4D- Thought"), and high-dimensional parietal (Rizzolatti) intel- lectual intuition (" $5 D+$-Action"), as balanced according to Richard Sorrentino's prime motivator trait (Un-)Certainty Orientation ("UO-versus-CO") interacting with "Mood". The two mentally processed transitions between these low- and high-dimensional domains, "4D-T $\sim$ " and " $5 D+-\mathbf{A} \sim$ ", are complexity-reductive Perception $\mathbf{P}\{\mathrm{A} \rightarrow \mathrm{T}\}$ and -expan- sionist Intention $(\mathbf{I}\{\mathrm{T} \rightarrow \mathrm{A}\})$, from which two kinds of lear- ning feed into "4D-T $\sim$ " for decision. Specifically in early $\mathbf{A W}$ the not just predictive, but incentive among Pavlovian cues putatively promises discounts in effort which foster intentions for worth-appropriative moves: $\mathbf{I}\{\mathrm{T} \rightarrow \mathrm{A}\}$. As "UO-versus-CO" to date seems homologous to the more sign- or more goal-tracking dimension ("ST-versus-GT") in rats. Since ST is controlled by the thalamic paraventricular nuclei and GT e.g. by the hippocampus, putative intruding mast cells might cause the depressive reversals in orientation, establishing mast cells as bio-economical agents.
\end{abstract}

Keywords (Un-)Certainty Orientation, Sign-tracking, Goal-tracking, Computational Psychiatry, Relational Complexity, Neuro-economics, Prediction Error, Cortico-subcortico-thalamo-cortical Circuits, Mast Cells, Mixed Bipolar Disorder

\section{Introduction}

The second part of this essay [2] proposing a more integrated and developed classical framework related to temperamental and anxio-affective "appropriations" in recurrent sequential waves, and attracted by permutated states, "dyn4-TAM-cube", (see abbreviation code ${ }^{\mathrm{i}}$ ), provides an encounter with currently rapidly unfolding convergent neuro-economics.

\section{Interfacing 4DT and 5+DA $\sim$ :Value" and "Worth"}

The opposite cognitive attitudes in facing unexplained complexity, which manifest as opposite human performances [1], in the dyn4-TAM-model [2] occur at the interfaces between low- and high-dimensional processing. The present proposal states, that in analogy to uncertainty-oriented humans (UOs), sign-tracker rats (STs), after engaging in the "perception of value" $\mathbf{P}\{\mathrm{A} \rightarrow \mathrm{T}\}$, perform vigorously in exploring anticipated potential discounts in effort, and secondary advantages in exchange of values, and goal-track$e r$-rats (GTs) instead in the "intuitive intention of worthappropriative moves" $\mathbf{I}\{\mathrm{T} \rightarrow \mathrm{A}\}$. Where the former sanguinics excel in reducing complexity, and thereby hopefully effort, into more sophisticated models of appropriation, the latter cholerics excel in keeping or expanding complexity. In order to substantiate this claim this convergent review aggregates more detailed structural analogies as a first step to hypothesis-testing.

Such temperamental variety, as other intra-group diversities [3], may favor fitness of groups and societies' welfare [4] and are at the core of conflict and cooperation.

Such value/worth-dualism also complies with the old stance, that the market value "exchanged (...) is the quantity 
of labor (...) commonly taken in producing them." [5]. Labor in the individual appears as "effort" - as reflected in e.g. tonic extracellular striatal dopamine [6]. Thus abstract value represents production costs, which ultimately consist of e.g. human effort.

This duality appears as biologically hard-wired. The phylogenetically newer anterior lateral OFC processes such abstract (monetary) "value"-rewards [7,8], which overcome subjective effort as incentive appetite probably signaling the opportunity of unusual bargain, while appropriated "worth" results in anticipatable, utility- reflecting affective "hot-spots" [9]. Hereby even the temperamental shapes of "utility" curves seem to be accounted for, yet "value" and "worth" are commonly considered as interchangeable [10].

\section{Dual vs. Mixed Motivational Updates}

Reward prediction error (RPE) signals, which update about the reliability ("precision") of cues (for opportunities), were first discovered in midbrain dopamine (DA) neurons [8, 11-13], and then in additional sites including - for punishment - the habenulae [14], striatum - also in humans [15].

The scope-specific single-step updating via eligibilitytargeted plasticity [11] accordingly is not a backward modulation, albeit still connected to specific needs. In fact pairing a CS(1) first with US(a) and then with US(b) is equally effi- cient for appropriative action, but blocks learning from a new $\operatorname{CS}(2)$ about $\operatorname{US}(\mathrm{a})^{\mathrm{i}}$. Rather than supporting an additional Konorskian general activation [16], such a block, deviating to another US(b), would allow to stick to an established joint cue about less effort in appropriating both.

A recent simulation [17] of sign-tracking (ST) underscores an antegrade capacity of the cue to reawaken a reward pertinent to a need, which then engages in a second, interre- lating process. The niche-dependent relative efficacy of goal- or sign-tracking is not considered and these "rewards" are added and not multiplied.

Only the reminder that appropriations are motivated by two processes [18], which in $d y n 4$ occur at "Intention" and "Perception" interfacing between $4 D \mathbf{T} \sim$ and $5+D \mathbf{A} \sim$ (Figure 1), which therefore ought not to be collapsed, seems to clarify several neuro-economical issues.

\section{Disincentivizing at the Interfaces}

Besides cognitive efforts, and many other intricacies of motivation [19], motor efforts impact future "rational" bestreward-for-least-effort-choices and subjective evaluations (like regret) through a same network. This correlates with reward and inversely with effort and involves SMA, itself corresponding to avoidance, and dorsal ACC's caudal portion for calculating motor costs. Not decision for action, but seeking of reward is activated by the vmPFC ${ }^{\mathrm{i}}[20]$.
As dissociated appear the shape and site of the actiondevigorating impacts a) of expenditure of effort, which is lesionable at the ACC (in the cortico-subcortico-thalamo-cortical circuit, CSTC, for $5+D \mathbf{A}$ ) or by unilateral sites of $\mathrm{mPFC}$ in rats [21], and $\mathrm{b}$ ) of delayed reward, which is lesionable at OFC (in the CSTC of Mood) [22]. While ACC and the anterior insula (aINS) perceive, $\mathbf{P}\{\mathrm{A} \rightarrow \mathrm{T}\}$, efforts [23] from $5+D \mathbf{A}$, delays might allow worries about extra efforts (4DT), to dis-incentivize, less $\mathbf{I}\{\mathrm{T} \rightarrow \mathrm{A}\}$, at the ventral striatum and the vmPFC. At least for STs effort-related fatigue usefully prevents further losses by stopping exploration of tempting cues [24].

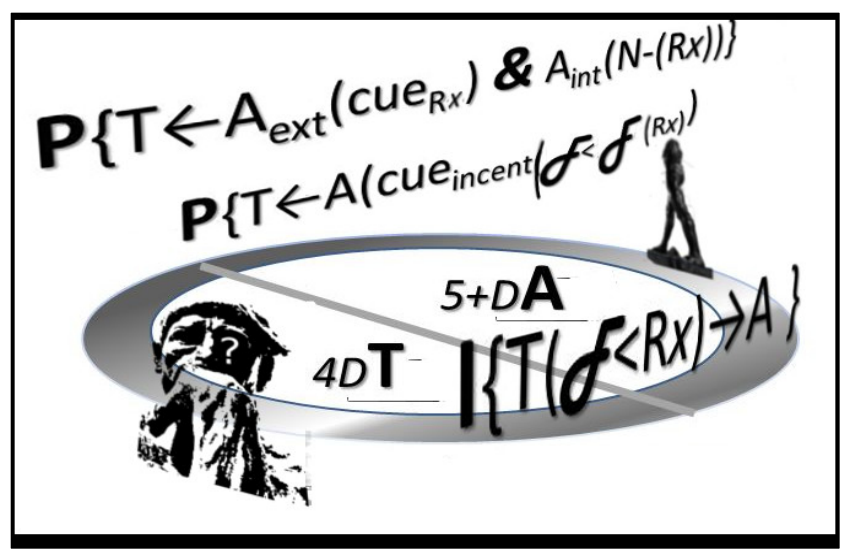

Figure 1. The cycle alternating $4 D$-Thought and $5+D$-Action, as illustrated through the "Thinker" and "Marcher" by Auguste Rodin, hides Appropria- tive Waves (AWs). At its first transition of Perception of external and internal feedbacks from effected change, some signals become contingent reward-x-specific cues, $\mathbf{A}(\operatorname{cue}(\mathrm{Rx}))$, inspiring the early $\mathbf{A W}$. Some of these become incentive cues of a different kind, which hint to a learned discount in the expected appropriative effort $(\boldsymbol{F})$. Intention urges for action when the expected cost, felt as effort $(\boldsymbol{F})$, is expected to be more than matched by the perceived reduction of Need by reward $\mathbf{R x}$ as $5+D-\mathbf{A}$ int $(\mathbf{N}-$ $\mathbf{R x}$ ).

Less effort as a negative reinforcement might provide a further "facilitation of a specific form of neural computation that results in conditioned approach behavior" also by mesolimbic dopamine, which here would not act as an anticipator of reward [25].

The principle of least effort also guides many decisions when building Intentions (I(T) $\rightarrow$ A) to act. As a loss-minimizing strategy - under interacting conditions of exhaustion and scarcity [26] - it is computed at the frontal pole as effort under risk [27]. In $d y n 4$ cues instill "Hope" to over- come the effort (transition "e" in part 1, Figure 3). Maximal own expendable specific need-proportionate effort ("Effme") therefore remains a crucial ceiling parameter, and the inverse of "value to $m e$ ".

While decisions localize to the OFC, foragers rapidly adapt their means or goals to changing surrounds through such a function of possible maximal effort and attainment through least effort, i.e. of "resources and opportunities." Herein the dorsal ACC [28] and the posterior cingulate cortex may at times signal the "pressure to pursue unlikely choices" - preferred by uncertainty-orientated STs [29]. 


\section{Prediction of less Effort or of Reward}

The ubiquitous "reward prediction error" (RPE) in most current accounts (but not in all experiments) could probably be smoothly replaced by a RPE normalized into $\mathrm{RPE}(-\Delta \% \text { Effme })^{\mathrm{i}}$ through multiplication with a ratio expressing the reward-specific maximal expendable effort, integrating past specific expenditures and regrets, and also the present "energetic state" [26], divided by the presently anticipated, at times negative, discount, as indicated by incentive cues.

The perception of the cue is temporally closer to the evaluation of anticipated effort, and therefore more easily associated with it, than the outcome in terms of utility (,worth"), apparent only after consumption. This worth divided by recent effort answers to the question "Was it worth the effort?" - risking regret [31] and updates the net RPE [32].

\subsection{Common and Individual Economic Comparison}

The need for comparison of rewards, often without a "common quality", calls for a ranking on a "common scale of values", on which the encoding of the RPE as "subjective value" is proposed as a, questionably, "ideal way" of steering economic decisions [31]. This "value" in reality though, as we can see, is a variable composite of worth (utility) and, at times incentive, value (effort), which is hidden behind of- ten dichotomic decisions. The variation of rewards in only one attribute is said not to allow the "isolation" of subjective preference - as far as sooner, more certain, and more should be preferred as better [31]. But beyond this we want what we like at discounted objective and subjective effort, thus the RPE changes to the residual RPE( $-\Delta \%$ Effme).

The closing e.g. consummatory end of the AW perceives the feedback $\mathbf{P}\{\mathrm{A} \rightarrow \mathrm{T}\}$ from $5+D \mathbf{A}$-led actions through evoked external and internal reactions, and activates instrumental learning. The update of $\mathrm{RPE}(-\Delta \% \mathrm{Effme})$ in $4 D \mathbf{T} \sim$ instead learns from spared, or increased, momentaneously anticipated effort, not from outcome $[8,11]$.

Accordingly ventral striatal neurons signal "reward" or rather RPE( $-\Delta \%$ Effme) before the rat's decision, the OFC only afterwards.

In market economics goal-specific objective effort, being the essential aversive variable related to appropriation, can be called "value", and sellers initially cash in on unaccustomed economies in effort since hereby they can buy "any" good representing more effort (value) with less effort, which on average holds true after transformation into subjective residual value represented by $\mathrm{RPE}(-\Delta \% \mathrm{Effme})$. In $d y n 4$ this momentaneously advantageous (positive) reduction of value figures as perception of a resource-saving cumulative 1-D-index of net appropriative experience relevant to the early AW-module Worry-T $\sim / \mathrm{a} \sim / \mathrm{m} \sim$. The dynamics of actions and the individual utility of things and services ("worth") instead attain to $(5+D-)$ Action.

That such acquired evaluative neo-Pavlovian "reflexes" obey to a ceiling of effort may find support in the resurrection of memory and learning in the study of primary sensory cortices [31]. It also seems even compatible with the various trait-like marginal utility curves [31] generated from "rational choice" via the unlikely "definition of value" as that from which "one can't get enough of" [11] in the pure monetary form. Nor anything formally scrunches thereafter when "utility is taken to be correlative to (...) want" - or by collapse with "worth" - what "a person is willing to pay" for satisfaction [33], in some other currency. Finally, since UOs, and presumably STs, are attracted by the unknowns of computable risk calling for modeled discounts in effort, they can be expected to enjoy the pure unsaturable monetary shape, of which imponderable worths only cause impure inflections.

\subsection{The Divisionary Focus of Habits}

This dualism of processing styles, here reflected through "UC-CO-orientation", is primarily non-habitual and thus different from the two "systems": either "quick, intuitive, and effortless" or innovative "slow, analytical, and deliberate" - thereby "overcoming intuition." [34]. In $d y n 4$ these map to, at first non-habitual, intuitive ways of $5+D \mathbf{A}$ and to more conscious symbolic processing in $4 D \mathbf{T}$, often struggling with what it perceives $(A \rightarrow T)$ of the complexity of $5+D$-Action and reaction.

Such model-based learning (MBL) besides the testing of hypotheses by relational thinking nevertheless also involves more Gestaltian [35] 4D-pattern searches, than even intractably costly searches through trees [36].

\subsection{When Scare Prefers Grasp over Model}

Only the dorsal ACC and the aINS [37] related to $4 D \mathbf{T} \sim$ and $\mathbf{M} \sim$, not the parietal cortex for $5+D \mathbf{A}$, harbor the highly intuitive rapid Von Economo-spindle cells [38], which might have a role in the reductionist grasping "Thought-aboutAction" $\mathbf{I}\{\mathbf{T} \rightarrow \mathrm{A}\}$ that provides newly adaptive fast-andfrugal heuristics. Such prove successful under both habitual and erratic circumstances [39] and are triggered by often just one cue providing "model-free" learning (MFL). Unexplained adverse complexity via input from locus coeruleus can block experienced model-based functioning in the ACC in favor of such erratic behavior, whereby, at times "naturally" simple-minded $\mathbf{C O}$-actors [1] become as unpredictable as their surrounds.

\subsection{When Modeling Becomes Useful}

Yet when routines stop working, UOs are needed for their renewal. Then even the liking system adapts: once cake is lacking you'll like bread! (Un-)Certainty-orientation theory [1] shows, that the related affective valences $(\mathrm{M} \sim)$ cannot be taken for granted, but reflects a stable cognitive trait.

The Uncertainty- oriented (UOs) are enabled to maintain the effort required for the conceptual reduction of the complexity of reality by their higher threshold for cogniti- 
ve-effort-related dysphoria, and by their, at times even high intellectual pleasure, Flow [41] denoting the process from Bliss to Interest in $d y n 4$.

The Certainty-oriented (COs), being unblessed by opportunity-optimizing modeling tasks, instead use rapid reductive "chunking" into essentially simple commands, to govern, intrinsically complex (!), habits.

While lack of mental flexibility can lead to apparent $\mathbf{C O}$, this usually comes with some loss of intelligence, which is not a feature of COs [1], but rather due to disturbances at the medio-dorsal thalamus [42]. The focus on such cognitive efforts presently rejuvenates psychiatry $[43,44]$.

\subsection{Collapsing Duality by Arithmetical Lumping}

One account of the ST-problem [36] avoids this double character, or "disunity" [45] of "value" or "worth", by proposing a halfway mixed dual system, whereby the STs are judged by the standards of the cage to be underperforming. MFL through sequential "hot-or-cold"-attempts, here represents "both habits and incentive salience" of Pavlovian "reflexes", while tree-comprehensive permutational, alias model-based, 4D-T-learning (MBL) supposedly relates "to goal-directed valuation, be it instrumentally or in Pavlovian settings". This commixture, ensuing from a crude reduction of intentional planning, cannot represent habits as entrenchment of instrumental learning nor decide the issue.

\subsection{Mood Interacts with Attitude towards the Not-yet-explained}

When it comes to positive, or negative, affect, what is interesting therefore is, that in the COs the valence of $\mathbf{M}$ decreases with increasing $4 D \mathbf{T} \sim$, whereas the UOs enjoy intellectual adventure proportionally [1]. Actually $\mathbf{M} \sim$ interacts with (Un)-Certainty-orientation: while UOs or COs are defined under the premises of a longing for "maxi- mal achievement", under the clinically depressive premises of a minimization of further losses, the two extreme types, at a certain point of prudence, switch into their mirror cognitive style [46, p.6]. Rats who have lost goals [47], or which know them for longer [48], switch from GT to ST, and certain "animals shift their preference from stable to variable food sources under (...) increased physical effort or falling energetic(s)."'[26]. Furthermore both orientations gain with high spirits, which steepen their opposed regressions.

Yet the yet-to-be-explaineds in foraging become dramatic only on arid, not on lush meadows, so at the end of despair COs, after transient UOs-ness, would become COs again, sticking to live-saving solutions. Yet goal-tracking rats (GTs) with empty pots would start searching farther away than desperate STs.

Teasing through contextual unknowns increases ST further [50-52], maybe because then cues signal lesser efforts unreliably [53]. Tracking-attitude may also depend on status, which is partly inborn: Dominant members often eat first and submissive members are more successful if they use innovative hypotheses, i.e. if they look more out for cues, than for the food proper, since in the first case they may eat unnoticed by the dominants, while in the second case, they may end up only knowing where the food is others eat.

\subsection{Hiding Circularity}

The circular account is obviously lacking in the recent Bayesian "Active Inference" model, which seemingly solved circular explanations of "reward", whereas this circularity just mirrors the essence of AWs informed by attributes of homeostasis or growth and as such should not be solved. The model in fact makes unpredictability, precision and salience collapse into "Active Inference" or what midbrain DA supposedly codes for, conveying how (active) "perception minimizes exteroceptive prediction errors and action minimizes proprioceptive prediction errors." [54]. The model in fact reflects the again truly marvelous discovery, that certain dopamine neurons under conditioned stimuli proportionally code for unpredictability of reward [55], but unpredictability unduly replaced reward and salience, whereas reality is more complex [13].

At least in the cortex response variability furthermore seems not be a solid foundation, since any stimulus causes its decline [56]. Albeit unpredictability, precision and salience determine the value in finance industry, they do not account for all facts in the life of rats.

\section{Mast Cells, Histamine, and Thalamus}

Mast cells (MCs) enter the brain during development, and these cells are replenished [57] or augmented by additional MCs which rapidly immigrate upon signals, which reflect social events, germs, drugs or physical changes [58] or, why not, sexual rubbing. Cerebral MCs are usually found to be scarce, yet most densely present at the thalamus, the habenulae, the olfactory bulb, and within the meninges. Via the braking habenulo-mesencephalic loops [59] MCs guard the blood-brain barrier $[60,61]$ or trans-granulate into neurons [62], and thus probably modulate incentives.

The perivascular access to the parenchyma of these sites is wide open in the subcortical [63], but obliterated in the cortical locations. The induction of MC degranulation in the thalamus of rats caused excitation ( $70 \%$ in females, $11 \%$ in males), or inhibition (7\% in females, $33 \%$ in males) of thalamic neurons [64]. Positive affect accompanies the behavioral invigoration triggered by MCs under several social circumstances, e.g. during courtship [65] in the medial habenulae. Female rats after cohabitation increase thalamic MCs within the medial geniculate and four other thalamic nuclei [66], whereas in mice not thalamic, but meningeal degranulation of MCs correlates with wakefulness and stimulatory tone in the CNS [67].

\subsection{Mast Cells and Thalamo-frontal Driving Feedbacks}

Dominant thalamo-frontal influences have been recognized in several domains [68-70]. These occur within the 
largely segregated, and thus dimensionally orthogonal, CSTCs [71], wherein cortical inputs to the basal ganglia are conveyed back to the cortex via the thalamus. Several of the many MC mediators [72] and effects could plausibly modulate the thalamus. While within the CSTCs the striatum is driven through glutamate by plentiful excitatory input from the $\mathrm{PFC}$, and by thalamo-striatal connections, MCs intriguingly only potentiate excitotoxicity via histamine (HA) [73], but are not glutamate-releasers, while requiring it for degranulation [74].

Nevertheless HA, commonly of MC origin, selectively potentiates N-methyl-d-aspartate receptors (NMDARs $\mathrm{i}^{\mathrm{i}}$ ) allosterically on a magnesium-sensitive NR2B ${ }^{\mathrm{i}}$-site [75] also involved in hallucinogenicity [76]. Such an increase of glutamatergic activity could plausibly impact on the functionning of CSTCs. While brain HA was normal in mice deficient in MCs, HA in rats was shown to stem from MCs up to $90 \%$ in the thalamus and to half in the brain [77]. The latter findings presumably also reflect a more activated state of MCs, wherein large amounts are secreted. Rat cerebral MCs were nearly all thalamic and specifically found in three areas and in the sign-tracking-related paraventricular nucleus of thalamus (PVT) [78].

\subsection{Mast Cells as Agents with Destination and Destiny}

It is tempting to investigate, wither cohorts of MCs, after peripheral priming of destination and destiny, would often migrate to the brain, where they would lastingly influence subcortical and cortical modules. In the striatum they interact with perivascular nerves, which are the fastest first responders for midbrain DA [79], or with cells of the neuro-vascular unit. Thereby physiological inflammatory processes could be pushed beyond temperament to "affective temperaments" [80], anxio-phobo-affective diagnoses or to soft, yet often deteriorating, bipolar mixed states [81].

Specifically the depressive switch into opposite tracking or (Un-)Certainty $[1,46]$ mode could be modulated by MCs primed to cause "depression" (instead of hypomanic lesional "vigor") when reaching the PVT, via the thalamo-perforate and thalamo-geniculate arteries.

The PVT in any case achieves its importance for cue-reward pairing through its broad subcortical and prelimbic cortical afferents and glutamergic efferents [82].

\section{Scopes and Outlooks}

The achievement of logically expressed convergent highquality research is a daunting task, especially if practical clinical utility remains a goal. Huge global projects like the Research Domain Criteria (RDoC) initiative are under way [83], which astonishingly removed movement from the classical triad [84]. Furthermore especially the understanding of intrinsically dimensional topics, e.g. of CSTCs providing dimensional data, seems relevantly hampered by the habitual avoidance of direct acquisitions of "unplugged" i. e. intact patterns, conservable e.g. through the Configural Frequency Analysis of Gustav Lienert [85, 86]. This intriguing neglect could be related to UC-orientation [87].

This essay, which takes advantage of the author's tiny context, strives to contribute a sketch of an anxio-affective framework for such convergence to epistemiology and clinical talk alike, dyn 4 being also progressively expanded to dyadic or family system relations. The essay focuses on an Aristotelian geometric classically triadic dyn4-T-A-Mmodel newly interpreted as contrast between private low-, and public high-dimensional processing. The comprehensive $\mathbf{A W}$, as inscribed in the cube and attracted by its dichotomic permutations, apparently has not been proposed as the basic sequence of behavior before.

\subsection{Triadic Models in Clinical Psychology}

An entwined "adolescent" triadic model [88,89], which centered on maturing balances of self-control [90], had instead cut across the T-A-M-dimensions in a not comprehensively orthogonal way. It generated a three composite factor balance between a) a mainly subcortical cognitively (actually movingly) impulsive non-delaying approach driven by reward, stemming even from "risk taking" (Joy-t $\sim \mathrm{A} \sim \mathrm{M} \sim$ ), b) a prefrontal cognitively reflected overall control $(\mathbf{T} \sim)$, and, beyond "dual systems", c) an amygdaloid emotionally deranged avoidance $(\mathbf{a} \sim, \mathbf{m} \sim)$. All the same e.g. it doesn't accomodate amygdalar salience or striatal expectancy [91] or the affective temperaments [92] well - nor the "inextricable" "interactive dexterity" emerging from studies, not allowed to be constrained into mechanistic orthogonality [93], albeit maybe just this would support the sought independence from valence, besides providing systematic complex predictions amenable to non-tautological falsification. Classically triadic instead is the influential associative, sensori-motor, and limbic tripartite division [59], albeit some sensations are low-dimensional.

\subsection{Are Neuro-economics "Dual or Not"?}

Intervening also into the present (neuro-)economical debate this essay calls for "circular" experiments avoiding undue "collapse" between low-dimensional "value"/effort and high-dimensional "worth"/utility. This is now strongly supported by the first localization of the positive human interactive "value-to-utility transformation" to the inversely activated dorsal anterior mid-cingulate cortex (dmPFC). The connectivity of this is positive with the probably uphill inferior frontal gyrus [94], related e.g. to perceptive "confidence" (certainty) [95], and negative with the probably downhill Nac providing intentional subjective "valutation". Within the OFC instead "value" seems stored behind, and "worth" in front [96]. Others shed doubt on the necessity of emotions as mediators of mesolimbic dopaminergic effects e.g. on feeding, but explore a more abstract "facilitation of a specific form of neural computation" [97], maybe an 
expansion of complexity.

Impressive reviews of transfer $[98,99]$ concede that despite guaranteed rewards, cues still work, whatever the "worth" [100], while others focus on "efforts" [101]. Importantly the "dual" arguments also apply when "worth" equals inviolacity [102].

By conceiving the incentivity of cues to be due to opportune effort-reducing and thus facilitating means signaled by the cue, their three [103] attributes - attractivity (for agent's attention or approach), instigation of effort to reach them, energizing of appropriation of reward - can be accounted for.

An orthogonal conceptionalization of the segregated albeit cortico-cortically linked CSTCs and their "intentional" function is maintained in some frameworks, at least for $\mathbf{A} \sim$ and $\mathbf{M} \sim$ [104], yet in a collapsed way avoiding $\mathbf{T} \sim$. Also the "orthogonalization" between motricity and reward again avoids the duality of $4 D-\mathbf{T} \sim$ and $5+D-\mathbf{A} \sim$ and just deals with $5+D-\mathbf{A} \sim$ and its first derivative: in fact more experimental distinction of MBL and MFL is being asked for [105].

\subsection{Habits Are Not Always Rapid or the Primary Issue}

Within the dyn4-framework, "models" are created in 4D-T with cognitive effort, but incentivated by the perspective of a variously [106, 107] tempting discount in antici- pated appropriative $5+D$-A $\sim$-related mainly motor effort, as signaled by cues functioning in such a model.

Motor-related habits [108], albeit dopaminergically [109] crystallized, are still complex programs reformatted away from globus pallidus [110] through various processes, e.g. TGF $\beta$ - [111] or NMDAR- [112] activity on striatal DA-neurons. The lack of the latter glutamatergic input slows down learning, social contacts and forced swimming, but not effortful performance [113].

Some neuro-economically engaged clinicians say themselves not yet content [114] with their differently dual complexity MBL/MBF-approach contrasting "more complex", "goal-directed" MBL-based behavior with alternative habitual MFL-based decision making [115]. They e.g. showed that rises in ventral striatal (VS) DA correlate with MBL-related "signatures" in dIPFC and inversely with MFL-related encoding in VS [115] - both being conceived as $4 D$-T $\sim$ in $d y n 4$. Their alternative habitual MBL-pro- cessing instead as such in $d y n 4$ would remain "complex" as related to $5+D$-A $\sim$-Action, despite requiring less $4 D$-T $\sim$ re- lated conscious steering or being shielded from outcomeperceiving feedback. This delayed habitual reformatting by repetition may actually detract from the problems collapsed neureconomics encounter in mental care.

The sufficient checking of a purportedly rapid less effortful intuitive system-1 $(5+D \mathbf{A})$ by a more reflective system-2 in otherwise biased decisions, has been strongly complemen- ted by a core role of even less intuitive numerical abilities (4DT) [116].

\subsection{Neurobehavioral Complexity Changes and dyn 4}

Following dyn4 it would have to be explored wither the CSTCs involving the ACC assigned to $5+D$-A really show a higher e.g. fractal dimensionality than the one involving the dlPFC mapped to $4 D$-T. In fact the dorsal ACC itself already produces neuro-economical [117] reductive models of con- flicting past and present experience [118] ready to feed decisions to be taken in dIPFC, linking contexts with appropriative, and therefore lastly motor strategies by producing a rich "task space" [119].

Since appropriation is the organizing principle in dyn 4 motricity $(5+D \mathbf{A})$ is in command of secondary parietal or primary motor areas. Similarly the CSTC involving OFC / vmPFC [120], and not the "limbic systems", represents Mood, as they master economical emotions [121] and integrate emotionally valenced "worth" to command appropriations [122].

The CSTCs themselves being feed-forward structures show an about 500-fold quantitative neuronal reduction in "complexity" between striatum and the pre-thalamic inhibiting output components. Of these the substantia nigra (SNr) e.g. may "gain control" over cortical feedback when sparing explorative efforts [123], braking "complicated" $5+D \mathbf{A}$. Ro- dent-primate homologies of CSTCs are many and also rela- ted to psy chiatric models [124].

The present $d y n 4$-account also implies that the alternating coordination between $4 D$-T- and $5+D$-A-processing is an enlightening prerequisite, beyond basic divergence and funneling, for any functional brain activity. This occurs within $4 D$-T and is often dealt with as top-down attention. Recent theoretical shifts towards considering the dorsal attention network (DAN) within the fronto-parietal cortices as a common substrate of "internal attention" sustaining as variegate functions as working memory, episodic retrieval of percepts, and intentionally complex mental imagery [125] supports this crudely mechanistic prediction on a high level of sophistication.

\subsection{Effortful Controls of Thought, Action, Mood}

We tend to fuse the concepts of subjective effort - the emotion of cost - as the felt passive brake on expenditure of resources, and again the overcoming active effort throughout the initiation and maintenance of effort-full processes. The steering of motor-costs is primordial, while the pleasuresystems and their hot-spots in evolution are small and marginal [126]. In humans though the costs of emotions, like the one from the urge of want, and their cognitive costs can become predominant. Thus, besides some focus on duration [127, 128], mainly the cost of suppressing emotions is monitored [129]. Fortunately affect dynamics are taking momen- tum also in the case of a likely alias of increased emotional effort suspected to be a pre-depressive signature of decoup- ling from usual functional connectivity: rigid emotional inertia [130]. 
These modules related to effort-ful appropriation have just been assembled in a formidable review [131]: The ventral striatum (VS) including the nucleus accumbens (NAc) activity likely is due to a momentaneous internal Perception of the opportune simple ratio of utility to effort, which continues when utility reaches a ceiling, helped by the midbrain. The VS invigorates appropriative action and the momentaneous changes in dopamine correlate with the willingness to work, which correlates with incentive cueing, even in absence of reward! Demanded high-effort choices, which need permission by the ACC, instead activates the amygdala, which seems to aid in encoding of relevance of the former inner and external Perceptions. It gives rise to urges, also in associative learning, whereby DA is released in the NAc, and the ACC is instructed to allow for high-effort expenditures. The amygdala overall acts as a conservative or investing expense controller in front of the temptations provided by the VS.

The dorsal striatum plans, decides, and automatizes motor behavior often into habits, while it also monitors internal metabolic and even external nutritional ressources. As a result it encodes specific energetic prerequisits for appropriation. Mice without DA instead die from aphagy, while hedonics and spatial learning of food remained intact. In dyn4 this preparation of Action corresponds to Intention. Within the dopaminergic midbrain the VTA and SNr interact with the striatum and thereby seem to provide the expected average opportunity on appropriation with the specific effort. Yet the amphetamine-sensitive emotional drive, as computed from the latter costs and delays combined with ,subjective value" (worth) and the variable confidence in consequential Intentions, is provided by the vmPFC. The ultimate decision is taken around the intraparietal sulcus.

In $d y n 4$ this corresponds to Interest or Worry leading via Application or Remediation to Pursuit [2, Table 1].

The supplementary motor areas (SMAs) monitoring muscle contraction interestingly feeds into subjective effort, while through preparedness it may invigorate response or maybe inversely spare effort.

\section{6. Momentaneous Fluctuations Could Confirm dyn4}

This same review [131] then attracts attention to the meaningful information hidden in the momentaneous fluctuations in cognitive and physical effort. Albeit the speed-accuracy trade-off is pervasive, it becomes hidden in the context of higher rewards, by which both increase. In psychiatry instead the new validated concentration deficit disorder (CDD), former "sluggish cognitive tempo“, which has replaced most of ADHD-inattentive type, is not an executive disorder, but strangely reminiscent of a coupled inertia of $\mathbf{T} \sim, \mathbf{A} \sim$, and $\mathbf{M} \sim$, related to depression and refraining from higher intensities in all three dimensions [132].

In dyn 4 accurate distances are a result of $5+D \mathbf{A} \sim$, while $4 D \mathbf{T} \sim$ is related to appropriations in a vage future and their speed. Reward-induced invigoration along the Appropria- tion-axis ,from Need to Pursuit“ in fact causes a symmetric intensification in $\mathbf{T} \sim, \mathbf{A} \sim$ and $\mathbf{M} \sim$. Through this analogy we start to consider coupled, usually skewed, simple harmonic oscillators (SHO as a mass-on-a-spring with $(-\mathrm{k} / \mathrm{m}) \cdot \mathrm{x}=$ $\mathrm{d}^{2} \mathrm{x} / \mathrm{dt}^{2}$ obeyed by $\sin (\mathrm{x})$ or $\left.\cos (\mathrm{x})\right)$ as a biaxial [133], not mono-axial [134] model of ,mood swings“. Hereby the above momentaneous fluctations of $\mathbf{T} \sim, \mathbf{A} \sim$, and $\mathbf{M} \sim$ are modeled, which putatively correspond to the three "affective" CSTCs. The CSTCs by virtue of their direct and (negative) indirect paths, in fact could be approximated as SHOs.

Silvain Tomkins modeling of emotions as analogue amplifiers of intensity and its first derivative over time with as prime role for muscle sensibility [135] here appears as very much to the point and compatible with $d y n 4$.

\subsection{Biopersonology and dyn4-TAM}

While dyn4-TAM can probably be best mapped to a bioamine-centered model of personality e. g. by Richard Depue [136], rapidly-acting ketamine-related or cholinergic antidepressants have deviated attention from these systems (see 7.5.).

The specifically cholinergic molecular loss of function in STs [137] points strongly to the fact that cholinergic systems support anti-distractive cognitive control, whilst also allowing for attentive shifts with reorientation to cues and cue-re- sponsive action [113], like approaching the goal!

Present psychological research on humans applies the concept of ,ST-to-GT“ [107] and could use cross-validating tests for „UC-to-CO“ $[1,46]$, while studying resistance to temptation or effort [106] would also test the here exposed hypothesis of homology.

\subsection{Mast Cells at the Reins of Appropriation?}

As to the own hypothesis, that the anatomical convergence of the three "affective" CSTCs at the thalamus might provide access especially for mast cells [138] intruding along the posterior arteries to modulate subcortical logistics, some few observations concur. Since STs are high in ventral HC myoinositol, and hereby dopaminergically incentivize Nac in Pavlovian approach [139], putative roles both of hippocampal mast cells [140] and of lithium [141], inhibiting IMPase [142], emerge, which hint to how the convergent framework dyn 4 could operate in affective disorders. In fact cues become less incentive under ketamine [143], the miracle antidepressant pro-drug which acts by upregulating AMPA-receptors [144], which happens to incite [145] or to calm mast cells [146], but does not affect midbrain DA [147].

The latest review on STs [148] points also to the lateral habenulae (LHb) [149-151], and thereby, see below, also to mast cells (MCs), as a part of the food-cue-induced "motive circuit", and its rapid adaptions. Within a larger network [152] they help in attributing salience [153] to the point, that 
the LHb drives the VTA and SNr during RPE [154]. The LHb specifically act as indirect $[155,156]$ strong inverse modulators [153] of the DA of the midbrain's SEEKING system [157], and the playfulness of STs is supported by the centrality of LHb for social play $[158,157]$. Conversely LHb and the medial habenula $(\mathrm{MHb})$ are sensitive in the nondepressed to present [159] or future punishment [160] up to learned helplessness [161,162], produce vegetative costs of emotions [163], and shrink [164, 165] especially in bipolar depression. Drugs inhibiting $\mathrm{LHb}$ reverse resistant depression [166].

As to MCs [58] they rapidily intrude after psychosocial events as acute activators e.g. into the LHb after repeated defeats [167], and with parenthood [168] into the reinforcing $\mathrm{MHb}$ of which silencing is aversive [169]. Mastocytosis finally is depressiogenic [170].

\section{Conclusions}

An essay "takes things from many sides without comprehending it fully."[171], and as a vivid genre of troubled times it takes high risks to fall victim to its own boldness by loosening cognitive control. Furthermore Karl Jaspers justly warned: "Theorizing has an atmosphere of its own." [172]. Progress in fact mostly, but not entirely, occurs through painstaking continuity of endeavors critical in seeking better lives, and the Ann Kelley's saga, certainly testifies to this. In the commemorative volume to her and also by her lab, which added successes with the STs and GTs rats, John D. Salamone contributed insights into the central role of Nac in bringing about effort-related choices [173]. This would also explain the common failures of RPE to behave in schizophrenia as computational psychiatrist, which build around it, were hoping for [176], and in this their "orthogonal" tautological Bayesian relations, which are akin to any reciprocal falsify- cation couple between theory and hypothesis, will not be of any comfort. Till date highly erudite accounts on "cues" [177] can still make it without "effort", but the two lines of enquiry will not continue on parallel tracks with little convergence for long.

The conceptual skipping of Thought and Intention in the Perception-Action models, even in their most erudite form [178] remains puzzling (to me), while the intricacies of relational cognitive processing explore the limits of complexity of Thought [179] - till now without a factoring-in of the "UC-to-CO"-algorithm. The Intention to think, act, and feel is certainly enriched by their "economical" braking by effort, and the second response component in midbrain DA-neurons, which codes reward value as a "numeric, quantitative utility prediction error", [180] could be a predictor of opportunity of less effort, and not of utility (worth), since it starts early enough to prevent "confusion with unrewarded stimuli and objects."

Especially in the NAc DA participates in effort-based choices among often many opportunities in the surrounds of the niche. Variability in active effort has been referred mostly to fluctuations in subjective anticipated effort [131]. Research on emotional effort is centered on the control or suppression of emotions, and maybe today research on the neuroeconomy of confidence [181] is most on track in this area, since confidence in a cheap simple heuristic model comes at a rarely relevant [39] price of error. Also dyn 4 knows the processes of Doubt or Confidence [2: Table 1] dealing with opposite interactions between modeling-in- $4 D \mathbf{T}$ and Mood. The proposal that the incentivity of such cues are about specific hope, that the expected required effort will be discounted, and that Hope in $d y n 4$ is the passage from Need-tam to Interest-TaM in $d y n 4$, is compatible with positive psychotherapy using incentive hope.

Survival depends on movement, movement on motivation, and motivation on cost-benefit analyses of active effort expressed in passively anticipated effort? Optogenetics on freely moving rodents will soon tell us more about this [181]. The SMA's feeding of muscle contraction into subjective effort [129] reminds us of the cutaneo-muscularly felt emotion theory of Silvain S. Tomkins [135] or recalls oro-facial mimics of "li(c)king“ [182] or the clenching of teeth to in- crease active effort, but it can't sustain the claim, that the felt quality of the „SEEKING“ system model would allow to collapse the duality of learning in approach [157].

A recent assembly of research on circuits of positive emotions [184], to which this paper originally was submitted as an elaboration of a poster, confirmed, that the important, because extremely basic hypothesis of a reinforcement or reversal of the prime motivator (Un-)Certainty-orientation of Richard M. Sorrentino [1,46] by valenced emotion, which reveals a constituting evolutionary link between cognition and emotion, and the mast cells are just only starting to attract noticeable interest in the mainstream of neurosciences. Therefore pioneers in ST-research [126] and MC-research related to the brain [58], Rae Silver, now leader in circadian rhythms, not fully by chance are immediate neighbors in a monograph on motivation [185], and the links likely also run via "clocked" [186] and "clocking" [187] MCs in brain [58] and other tissue [188] in relation to bio-economic metabolism [189] and its central "subjective" variable effort [190].

\section{Acknowledgements}

This work became possible through the legacy from my sister Fiorenza Hohl.

\section{Conflicting Financial Interests}

None.

\section{REFERENCES}

[1] R. M. Sorrentino. Uncertainty orientation: A theory where the exception forms the rule. Revista de Motivación y Emoción 1, 
$1-11,2012$ Online available from $\mathrm{http}: / /$ reme.uji.es/reme/1-sorrentino_pp_1-11.pdf

[2] G. R. S. Treviranus. For value or for worth? Part 1: Speaking syllogistic attractors of appropriations in a thoughtaction-mood-space. Universal Journal of Psychology, 5(2), 42-49, 2017.

[3] Trubenová, R. Hager. Social selection and indirect genetic effects in structured populations. Evolutionary Biology 41(1), 123-133, 2014. doi:10.1007/s11692-013-9252-5

[4] Plato. The Republic. Transl. B. Jowett. J. Manis (Ed.). The Electronic Classics Series Hazleton, PA: PSU-Hazleton. Online available from http://worldlibrary.org

[5] Anonymous. Some thoughts on the interest of money in general, and particularly in the publick funds,.. London, 1739 or 1740. Cited in: K. Marx, Capital, vol. one. Chp.1. Sect.4. The fetishism of commodities and the secret thereof. Annot. 9. [Transl. Ben Fowkes 1990. London: Penguin Books.], 1867.

[6] S. B. Ostlund, K. M. Wassum, N. P. Murphy, B. W. Balleine, N. T. Maidment. Extracellular dopamine levels in striatal subregions track shifts in motivation and response cost during instrumental conditioning. Journal of Neuroscience 31(1), 200-207, 2011. doi: 10.1523/JNEUROSCI.4759-10.2011

[7] Y. Li, G. Vanni-Mercier, J. Isnard, F. Mauguière, J. C. Dreher. The neural dynamics of reward value and risk coding in the human orbitofrontal cortex. Brain 139(Pt 4), 1295-1309, 2016. doi:10.1093/brain/awv409

[8] W. Schultz, P. Dayan, P. R. Montague. A neural substrate of prediction and reward. Science 275(5306), 1593-1599, 1997. doi:10.1126/science.275.5306.1593

[9] D. C. Castro, K. C. Berridge. Advances in the neurobiological bases for food 'liking' versus 'wanting'. Physiology, Behavior 136(0), 22-30, 2014. doi:10.1016/j.physbeh.2014.05.022/

[10] J. P. O'Doherty. The problem with value. Neuroscience, Biobehavioral Reviews 43(1), 259-268, 2014 doi:10.1016/j.neubiorev.2014.03.027/

[11] W. Schultz. Neuronal reward and decision signals: from theories to data. Physiological Reviews 95(3), 853-951, 2015. doi:10.1152/physrev.00023.2014

[12] H. M. Bayer, P. W. Glimcher. Midbrain dopamine neurons encode a quantitative reward prediction error signal. Neuron 47(1), 129-141, 2005. doi:10.1016/j.neuron.2005.05.020

[13] C. D. Fiorillo, M. R. Song, S. R. Yun. Multiphasic temporal dynamics in responses of midbrain dopamine neurons to appetitive and aversive stimuli. Journal of Neuroscience 33(11), 4710-4725, 2013.

doi:10.1523/JNEUROSCI.3883-12.2013

[14] E. S. Bromberg-Martin, O. Hikosaka. Lateral habenula neurons signal errors in the prediction of reward information. Nature Neuroscience 14(9), 1209-16, 2011. Erratum (print only) in: Nature Neuroscience 14(12), 1617. doi:10.1038/nn.2902/

[15] H. W. Chase, P. Kumar, S. B. Eickhoff, A.Y. Dombrovski. Reinforcement learning models and their neural correlates: an activation likelihood estimation meta-analysis. Cognitive, Affective, \& Behavioral Neuroscience 15, 435-459, 2015. doi:10.3758/s13415-015-0338-7

[16] L. H. Corbit, B. W. Balleine. Learning and Motivational
Processes Contributing to Pavlovian-Instrumental Transfer and Their Neural Bases: Dopamine and Beyond. In: E. H. Simpson, P. D. Balsam (eds.). Behavioral Neuroscience of Motivation. Current Topics in Behavioral Neurosciences. Vol. 27. (pp 259-289). Springer Int., Cham ZG, 2016. doi:10.1007/7854_2015_388

[17] S. Kaveri, H. Nakahara. Dual reward prediction components yield Pavlovian sign- and goal-tracking. PLoS One 9(10), e108142, 2014. doi:10.1371/journal.pone.0108142

[18] R. A. Rescorla, R. L. Solomon. Two-process learning theory: relationships between Pavlovian conditioning and instrumental training. Psychological Review 74,151-183, 1967.

[19] M. R. Bailey, E. H. Simpson, P. D. Balsam. Neural substrates underlying effort, time, and risk-based decision making in motivated behavior. Neurobiology of Learning and Memory. 133, 233-256, 2016. doi:10.1016/j.nlm.2016.07.015

[20] M. C. Klein-Flügge, S. W. Kennerley, K. Friston, S. Bestmann. Neural signatures of value comparison in human cingulate cortex during decisions requiring an effort-reward trade-off. Journal of Neuroscience 36(39), 10002-10015, 2016. doi:10.1523/JNEUROSCI.0292-16.2016

[21] P. L. Croxson, M. E. Walton, M. F. Rushworth, D. M. Bannerman. Unilateral medial frontal cortex lesions cause a cognitive decision-making deficit in rats. European Journal of Neuroscience 40, 3757-3765, 2014. doi:10.1111/ejn.12751

[22] M. C. Klein-Flügge, S. W. Kennerley, A. C. Saraiva, W. D. Penny, S. Bestmann. Behavioral modeling of human choices reveals dissociable effects of physical effort and temporal delay on reward devaluation. PLoS Computational Biology 11(3), e1004116, 2015. doi:10.1371/journal.pcbi.1004116

[23] C. Prévost, M. Pessiglione, E. Météreau, M. L., Dreher, J. C. Cléry-Melin. Separate valuation subsystems for delay and effort decision costs. Journal of Neuroscience 30(42), 14080-14090, 2010.doi:10.1523/JNEUROSCI.2752-10.2010

[24] R. Kurzban, A. Duckworth, J. W. Kable, J. Myers. An opportunity cost model of subjective effort and task performance. Behavioral and Brain Sciences 36(6), 661-679, 2013. doi:10.1017/S0140525X12003196

[25] S. M. Nicola. Reassessing wanting and liking in the study of mesolimbic influence on food intake. American Journal Physiology Regulatory, Integrative, and Comparative Physiology. 311, 5, R811-R840, 2016. doi:10.1152/ajpregu.00234.2016

[26] M. A. Miller, A. Thomé, S. L. Cowen. Intersection of effort and risk: ethological and neurobiological perspectives. Frontiers in Neuroscience 7, 208, 2013. doi:10.3389/fnins.2013.00208

[27] C. J. Burke, C. Brünger, T. Kahnt, S. Q. Park, P. N. Tobler. Neural integration of risk and effort costs by the frontal pole: only upon request. Journal of Neuroscience 33(4), 1706-1712, 2013. doi:10.1523/JNEUROSCI.3662-12.2013/

[28] B. Y. Hayden, J. M. Pearson, M. L. Platt. Neuronal basis of sequential foraging decisions in a patchy environment. Nature Neuroscience 14(7), 933-939, 2011. doi:10.1038/nn.2856

[29] N. Kolling, M. Wittmann, M. F. Rushworth. Multiple neural mechanisms of decision making and their competition under 
changing risk pressure. Neuron 81(5), 1190-1202, 2014. https://doi.org/10.1016/j.neuron.2014.01.033.

[30] C. Giorgetta, A. Grecucci, N. Bonini, G. Coricelli, G. Demarchi, C. Braun, A. G. Sanfey. Waves of regret: a meg study of emotion and decision-making. Neuropsychologia 51(1), 38-51, 2013.

doi:10.1016/j.neuropsychologia.2012.10.015

[31] W. R. Stauffer, A. Lak, W. Schultz. Dopamine reward prediction error responses reflect marginal utility. Current Biology 24(21), 2491-2500, 2014.

doi:10.1016/j.cub.2014.08.064

[32] B. W. Balleine. Sensation, Incentive Learning, and the Motivational Control of Goal-Directed Action. In: J. A. Gottfried (Ed.). Neurobiology of Sensation and Reward. Boca Raton, FL: CRC Press, 2011.

[33] A. Marshall. Principles of Economics. An introductory volume. 8th ed. London, UK: Macmillan, 1920. (p.78).

[34] A. L. Alter, D. M. Oppenheimer, N. Epley, R. N. Eyre. Overcoming intuition: metacognitive difficulty activates analytic reasoning. Journal of Experimental Psychology: General 136(4), 569-576, 2007. doi:10.1037/0096-3445.136.4.569

[35] P. R. Montoro, D. Luna, J. J. Ortells. Subliminal Gestalt grouping: evidence of perceptual grouping by proximity and similarity in absence of conscious perception. Consciousness and Cognition 25(1), 1-8, 2014. doi:10.1016/j.concog.2014.01.004

[36] Q. J. Huys, P. N. Tobler, G. Hasler, S. B. Flagel. The role of learning-related dopamine signals in addiction vulnerability. Progress in Brain Research 211, 31-77, 2014. doi:10.1016/B978-0-444-63425-2.00003-9

[37] L. Q. Uddin, J. Kinnison, L. Pessoa, M. L. Anderson. Beyond the tripartite cognition-emotion-interoception model of the human insular cortex. Journal of Cognitive Neuroscience 26(1), 16-27, 2014. doi:10.1162/jocn_a_00462

[38] H. C. Evrard, T. Forro, N. K. Logothetis. Von Economo neurons in the anterior insula of the macaque monkey. Neuron 74(3), 482-489, 2012. doi:0.1016/j.neuron.2012.03.003

[39] G. Gigerenzer, H. Brighton. Homo heuristicus: Why biased minds make better inferences. Topics in Cognitive Science 1(1), 107-143, 2009. doi:10.1111/j.1756-8765.2008.01006.x

[40] D. G. Tervo, M. Proskurin, M. Manakov, M. Kabra, A. Vollmer, K. Branson, A. Y. Karpova. Behavioral variability through stochastic choice and its gating by anterior cingulate cortex. Cell 159(1), 21-32, 2014. doi:10.1016/j.cell.2014.08.037.

[41] J. Nakamura, M. Csikszentmihalyi, M. Flow theory and research. In C. R. Snyder and S. J. Lopez, (Eds.), Handbook of Positive Psychology. (pp. 195-206). Oxford: Oxford University Press, 2009.

[42] S. Parnaudeau, K. Taylor, S. S. Bolkan, R. D. Ward, P. D. Balsam, C. Kellendonk. Mediodorsal thalamus hypofunction impairs flexible goal-directed behavior. Biological Psychiatry 77(5), 445-453, 2014. doi:10.1016/j.biopsych.2014.03.020

[43] A. Culbreth, A. Westbrook, D. Barch. Negative symptoms are associated with an increased subjective cost of cognitive effort. Journal of Abnormal Psychology 125(4), 528-536, 2016. doi:10.1037/abn0000153
[44] W. P. Horan, L. F. Reddy, D. M. Barch, R. W. Buchanan, E. Dunayevich, J. M. Gold, (...) M. F. Green. Effort-based decision-making paradigms for clinical trials in schizophrenia: part 2 - External validity and correlates. Schizophrenia Bulletin 41(5), 1055-1065, 2015. doi:10.1093/schbul/sbv090y

[45] S. B. Ostlund, B. W. Balleine. The disunity of Pavlovian and instrumental values. Behavioral and Brain Sciences 31(4), 456-457, 2008. doi:10.1017/S0140525X0800492

[46] R. M. Sorrentino, C. J. R. Roney. The uncertain mind: Individual differences in facing the unknown. Philadelphia: Psychology Press., 2000.

[47] M. J. Robinson, P. Anselme, A. M. Fischer, K. C. Berridge. Initial uncertainty in Pavlovian reward prediction persistently elevates incentive salience and extends sign-tracking to normally unattractive cues. Behavioural Brain Research 266(0), 119-130, 2014. doi:10.1016/j.bbr.2014.03.004

[48] C. S. Srey, J. M. Maddux, N. Chaudhri. The attribution of incentive salience to Pavlovian alcohol cues: a shift from goal-tracking to sign-tracking. Frontiers in Behavioral Neurosciences 9, 54, 2015. doi:10.3389/fnbeh.2015.00054

[49] D. J. S. Costa, R. A. Boakes. Context blocking in rat autoshaping: Sign-tracking versus goal-tracking. Learning and Memory 40(2), 178-185, 2009.

http://dx.doi.org/10.1016/j.1mot.2008.11.001

[50] P. Anselme, M. J. Robinson, K. C. Berridge. Reward uncertainty enhances incentive salience attribution as sign-tracking. Behavioural Brain Research 238, 53-61, 2013. doi:10.1016/j.bbr.2012.10.006

[51] M. J. F. Robinson, P. Anselme, K. Suchomel, K. C. Berridge. Amphetamine-induced sensitization and reward uncertainty similarly enhance incentive salience for conditioned cues. Behavioral Neuroscience 129(4), 502-511, 2015. doi:10.1037/bne0000064

[52] P. Anselme. Does reward unpredictability reflect risk? Behavioural Brain Research 280, 119-127, 2015. doi:10.1016/j.bbr.2014.12.003/

[53] A. Funamizu, M. Ito, K. Doya, R. Kanzaki, H. Takahashi. Condition interference in rats performing a choice task with switched variable- and fixed-reward conditions. Frontiers in Neuroscience. 9, 27, 2015. doi:0.3389/fnins.2015.00027

[54] K. J. Friston, T. Shiner, T. FitzGerald, J. M. Galea, R. Adams, H. Brown, R. J. Dolan, R. Moran, K. E. Stephan, S. Bestmann. Dopamine, affordance, and active inference. PLoS Computational Biology 8, e1002327, 2012. doi:10.1371/journal.pcbi.100232

[55] C. D. Fiorillo, J. K. Kim, S. Z. Hong. The meaning of spikes from the neuron's point of view: predictive homeostasis generates the appearance of randomness. Frontiers in Computational Neuroscience 8, 49, 2014. doi:10.3389/fncom.2014.00049

[56] M. M. Churchland, B. M. Yu, J. P. Cunningham, L. P. Sugrue, M. R. Cohen. Stimulus onset quenches neural variability: a widespread cortical phenomenon. Nature Neuroscience 13(3), 369-378, 2010. doi:10.1038/nn.2501

[57] K. M. Nautiyal, C. Liu, X. Dong, R. Silver. Blood-borne donor mast cell precursors migrate to mast cell-rich brain regions in 
the adult mouse. Journal of Neuroimmunology 240-241, 142-146, 2011. doi:10.1016/j.jneuroim.2011.09.003

[58] R. Silver, J. P. Curley. Mast cells on the mind: new insights and opportunities. Trends in Neuroscience 36(9), 513-521, 2013. doi:10.1016/j.tins.2013.06.001

[59] S. Ikemoto, C. Yang, A. Tan. Basal ganglia circuit loops, dopamine and motivation: A review and enquiry. Behavioural Brain Research 290, 17-31, 2015. doi:10.1016/j.bbr.2015.04.018

[60] P. Esposito, N . Chandler, K. Kandere, S. Basu, S. Jacobson, R. Connolly, D. Tutor, T. C. Theoharides. Corticotropin-releasing hormone and brain mast cells regulate blood-brain-barrier permeability induced by acute stress. Journal of Pharmacology and Experimental Therapeutics 303(3), 1061-1066, 2002. doi:10.1124/jpet.102.038497

[61] D. Ribatti. The crucial role of mast cells in blood-brain barrier alterations. Experimental Cell Research 338(1), 119-125, 2015.

[62] M. Wilhelm, R. Silver, A. J. Silverman. Central nervous system neurons acquire mast cell products via transgranulation. European Journal of Neuroscience 22(9), 2238-2248. doi: $10.1111 / \mathrm{j} .1460-9568.2005 .04429 . \mathrm{x}$

[63] Jones, E. G. On the mode of entry of blood vessels into the cerebral cortex. Journal of Anatomy 106(Pt 3), 507-520, 1970.

[64] P. Kovács, I. Hernádi, M. Wilhelm. Mast cells modulate maintained neuronal activity in the thalamus in vivo. Journal of Neuroimmunolgy 171(1-2), 1-7, 2006. doi:10.1016/j.jneuroim.2005.07.026

[65] X. Zhuang, A. J. Silverman, R. Silver. Reproductive behavior, endocrine state, and the distribution of GnRH-like immunereactive MCs in dove brain. Hormones and Behavior 27(3), 283-295, 1993. doi:10.1111/j.1365-2826.1992.tb00160.x

[66] L. Asarian, E. Yousefzadeh, A. J. Silverman, R. Silver. Stimuli from conspecifics influence brain mast cell population in male rats. Hormones and Behavior 42(1), 1-12, 2002. doi:10.1006/hbeh.2002.1799

[67] A. A. Larson, M. J. Thomas, A. McElhose, K. J. Kovács. Spontaneous locomotor activity correlates with the degranulation of mast cells in the meninges rather than in the thalamus: disruptive effect of cocaine. Brain Research 1395(0), 30-37, 2011. doi:10.1016/j.brainres.2011.04.033

[68] J. de Bourbon-Teles, P. Bentley, S. Koshino, K. Shah, A. Dutta, P. Malhotra, T. Egner, M. Husain, D. Soto. Thalamic control of human attention driven by memory and learning. Current Biology 24(9), 993-999, 2014. doi:10.1016/j.cub.2014.03.024

[69] B. B. Theyel, D. A. Llano, S. M. Sherman. The corticothalamocortical circuit drives higher-order cortex in the mouse. Nature Neuroscience 13(1), 84-88, 2010. doi:10.1038/nn.2449

[70] A. Nakhnikian, G. V. Rebec, L. M. Grasse, L. L. Dwiel, M. Shimono, J. M. Beggs. Behavior modulates effective connectivity between cortex and striatum. PLoS One 9(3), e89443, 2014. doi:10.1371/journal.pone.0089443

[71] M. S. Mega, J. L. Cummings. Frontal-subcortical circuits and neuropsychiatric disorders. Journal of Neuropsychiatry and Clinical Neurosciences 6(4), 358-70, 1994. doi:10.1176/jnp.6.4.358
[72] T. C. Moon, A. D. Befus, M. Kulka. Mast cell mediators: their differential release and the secretory pathways involved. Frontiers in Immunology 5, 569, 2014. doi:10.3389/fimmu.2014.00569

[73] S. D. Skaper, L. Facci, W. J. Kee, P. J. Strijbos. Potentiation by histamine of synaptically mediated excitotoxicity in cultured hippocampal neurones: a possible role for mast cells. Journal of Neurochemistry 76(1), 47-55, 2001. doi:10.1046/j.1471-4159.2001.00008.x

[74] E. K. Hamasato, A. P. Ligeiro de Oliveira, A. Lino-dosSantos-Franco, A. Ribeiro, V. Ferraz de Paula, J. P. Peron, A. S. Damazo, W. Tavares-de-Lima, J. Palermo-Neto. Effects of MK-801 and amphetamine treatments on allergic lung inflammatory response in mice. International Immunopharmacology 16(4), 436-443, 2013. doi:10.1016/j.intimp.2013.04.019

[75] A. Burban, R. Faucard, V. Armand, C. Bayard, V. Vorobjev, J. M. Arrang. Histamine potentiates N-methyl-D-aspartate receptors by interacting with an allosteric site distinct from the polyamine binding site. Journal of Pharmacology and Experimental Therapeutics 332, 912-921, 2010. doi:10.1124/jpet.109.158543

[76] E. K. Lambe, G. K. Aghajanian. Hallucinogen-induced UP states in the brain slice of rat prefrontal cortex: role of glutamate spillover and NR2B-NMDA receptors. Neuropsychopharmacology 31(8), 1682-1689, 2006.

[77] R. C. Goldschmidt, L. B. Hough, S. D. Glick. Rat brain mast cells: contribution to brain histamine levels. Journal of Neurochemistry 44(6), 1943-1947, 1985. doi:10.1111/j.1471-4159.1985.tb07191.x

[78] R. C. Goldschmidt, L. B. Hough, S. D. Glick, J. Padawer. Mast cells in rat thalamus: nuclear localization, sex difference and left-right asymmetry. Brain Research 323(2), 209-217, 1984. doi:10.1016/0006-8993(84)90291-9

[79] D. Afonso-Oramas, I. Cruz-Muros, J. Castro-Hernández, J. Salas-Hernández, P. Barroso-Chinea, S. García-Hernández, J. L. Lanciego, T. González-Hernández. Striatal vessels receive phosphorylated tyrosine hydroxylase-rich innervation from midbrain dopaminergic neurons. Frontiers in Neuroanatomy 8 , 84, 2014. doi:10.3389/fnana.2014.00084

[80] J. M. Himmelhoch. The sources of characterological presentations of mixed bipolar states. Clinical Neuropharmacology 15 (Pt. A) 630A-631A, 1992. Available online from http://journals.lww.com/clinicalneuropharm/ Citation/1992/01001

[81] G. S. Malhi, L. Lampe, C. M. Coulston, M. Tanious, D. M. Bargh, G. Curran, S. Kuiper, H. Morgan, K. Fritz. Mixed state discrimination: a DSM problem that won't go away? Journal of Affective Disorders 158, 8-10, 2014. doi:10.1016/j.jad.2014.01.008

[82] J. L. Haight, S. B. Flagel. A potential role for the paraventricular nucleus of the thalamus in mediating individual variation in Pavlovian conditioned responses. Frontiers in Behavioral Neuroscience 8, 79, 2014. doi:10.3389/fnbeh.2014.00079

[83] L. M. Williams, A. N. Goldstein-Piekarski, N. Chowdhry, K. A. Grisanzio, N. A. Haug, Z. Samara, A. Etkin, R. O'Hara, A. F. Schatzberg, T. Suppes, J. Yesavage. Developing a clinical translational neuroscience taxonomy for anxiety and mood 
disorder: protocol for the baseline-follow up Research domain criteria Anxiety and Depression ("RAD") project. BMC Psychiatry 16, 68, 2016. doi:10.1186/s12888-016-0771-3

[84] J. A. Bernard, V. A. Mittal. Updating the research domain criteria: the utility of a motor dimension. Psychological Medicine 45(13), 2685-2659, 2015. doi:10.1017/S0033291715000872

[85] A. von Eye. Configural Frequency Analysis - Methods, Models, and Applications. Mahwah, NJ: Lawrence Erlbaum, 2002

[86] G. A. Bogat, A. Von Eye, L. R. Bergman. Person-oriented approaches. 797- 845. In: D. Cichetti (Ed.). D. J. Cohen. Developmental Psychopathology, Theory and Method. 2nd Edition. ISBN: 978-0-471-23736-5. 1104 pages.

[87] G. R. S. Treviranus. Not grasping patterns as you should? Person-centered Configural Frequency Analysis, its bio-psychological avoidance \& the (high) costs of this. SSPE biannual meeting 2016. Poster session. University of Zurich. 24.06.2016. Online available from https://www.researchgate.net/publication/304580615

[88] M. Ernst, D. S. Pine, M. Hardin. Triadic model of the neurobiology of motivated behavior in adolescence. Psychological Medicine, 36(3), 299-312, 2006. doi:10.1017/S0033291705005891

[89] M. Ernst. The triadic model perspective for the study of adolescent motivated behavior. Brain and Cognition 89(0), 104-111, 2014. doi:10.1016/j.bandc.2014.01.006

[90] A. S. Heller, A. O. Cohen, M. F. Dreyfuss, B. J. Casey. Changes in cortico-subcortical and subcortico-subcortical connectivity impact cognitive control to emotional cues across development. Social Cognitive and Affective Neuroscience 11(12), 1910-1918, 2016. doi:10.1093/scan/nsw097

[91] L. H. Somerville, B. G. van den Bulk, A. C. Skwara. Response to: "the triadic model perspective for the study of adolescent motivated behavior". Brain and Cognition 89, 112-113, 2014. doi:10.1016/j.bandc.2014.01.003

[92] X. Gonda, G. H. Vázquez. Theoretical and clinical overview of affective temperaments in mood disorders. Psicodebate, Vol. 14, $\mathrm{N}^{\mathrm{o}} 2$ 2, 2014. doi:1010.18682/pd.v14i2

[93] B. J. Casey, A. Galván, L. H. Somerville. Beyond simple models of adolescence to an integrated circuit-based account: A commentary. Developmental Cognitive Neuroscience 17, 128-30, 2016. doi:10.1016/j.den.2015.12.00

[94] Y. A. Kurnianingsih, O. A. Mullette-Gillman. Neural mechanisms of the transformation from objective value to subjective utility: converting from count to worth. Frontiers in Neuroscience 10, 507, 2016. doi:10.3389/fnins.2016.00507

[95] M. T. Sherman, A. K. Seth, R. Kanai. Predictions shape confidence in right inferior frontal gyrus. Journal of Neuroscience 36(40),10323-10336, 2016. doi:10.1523/JNEUROSCI.1092-16.2016

[96] Y. Li, G. Sescousse, C. Amiez, J. C. Dreher. Local morphology predicts functional organization of experienced value signals in the human orbitofrontal cortex. Journal of Neuroscience 35(4), 1648-58, 301, 2015. doi:10.1523/JNEUROSCI.3058-14.2015
[97] S. M. Nicola. Reassessing wanting and liking in the study of mesolimbic influence on food intake. American Journal Physiology Regulatory, Integrative, and Comparative Physiology. 311, 5, R811-R840, 2016.

https://doi.org/10.1152/ajpregu.00234.2016

[98] L. H. Corbit, B. W. Balleine. Learning and Motivational Processes Contributing to Pavlovian-Instrumental Transfer and Their Neural Bases: Dopamine and Beyond. In: E. H. Simpson, P. D. Balsam (Eds.). Behavioral Neuroscience of Motivation. Current Topics in Behavioral Neurosciences. Vol. 27. (pp 259-289). Springer Int., Cham ZG, 2016. doi:10.1007/7854_2015_388

[99] E. Cartoni, B. Balleine, G. Baldassarre. Appetitive Pavlovian-instrumental transfer: a review. Neuroscience \& Biobehavioral Reviews 71, 829-848, 2016. doi:10.1016/j.neubiorev.2016.09.020

[100] R. Lehner, J. H. Balsters, A. Herger, T. A. Hare, N. Wenderoth. Monetary, food, and social rewards induce similar Pavlovian-to-instrumental transfer effects. Frontiers in Behavioral Neuroscience. 10, 247, 2017. doi:10.3389/fnbeh.2016.0024

[101] B. Studer, S. Knecht (Eds.). Motivation: Theory, Neurobiology and Applications. Progress in Brain Research 229, 2016. 1st Edition. Elsevier: London UK. 486 p. doi:10.1016/bs.pbr.2016.06.003

[102] K. Lloyd, P. Dayan. Safety out of control: dopamine and defence. Behavioral and Brain Functions 12(1), 15, 2016. doi:10.1186/s12993-016-0099-7

[103] T. E. Robinson, L. M. Yager, E. S. Cogan, B. T. Saunders. On the motivational properties of reward cues: Individual differences. Neuropharmacology 76(pt B), 450-459, 2014. doi:10.1016/j.neuropharm.2013.05.040

[104] Y. Saga, Y. Hirata, D. Takahara, K. Inoue, S. Miyachi, A. Nambu, J. Tanji, M. Takada, E. Hoshi. Origins of multisynaptic projections from the basal ganglia to rostrocaudally distinct sectors of the dorsal premotor area in macaques. European Journal of Neuroscience 33(2), 285-297, 2011. doi:10.1111/j.1460-9568.2010.07492.x

[105] M. Guitart-Masip, E. Duzel, R. Dolan, P. Dayan. Action versus valence in decision making. Trends in Cognitive Sciences 18(4),194-202, 2014. doi:10.1016/j.tics.2014.01.00

[106] B. T. Saunders, T. E. Robinson. Individual variation in resisting temptation: implications for addiction. Neuroscience \& Biobehavioral Reviews 37(9 Pt A), 1955-1975, 2013. doi:10.1016/j.neubiorev.2013.02.008

[107] S. Garofalo, G. di Pellegrino. Individual differences in the influence of task-irrelevant Pavlovian cues on human behavior. Frontiers in Behavioral Neuroscience 9, 163, 2015 doi:10.3389/fnbeh.2015.00163

[108] K. S. Smith, A. M. Graybiel. Habit formation. Dialogues in Clinical Neuroscience 18(1), 33-43, 2016.

[109] M. Aggarwal, J. R. Wickens. A role for phasic dopamine neuron firing in habit learning. Neuron 72(6), 892-894, 2011. doi:10.1016/j.neuron.2011.12.006

[110] E. Schechtman, M. I. Noblejas, A. D. Mizrahi, O. Dauber, H. Bergman. Pallidal spiking activity reflects learning dynamics and predicts performance. Proceedings of the National Academy of Sciences of the U. S. A. 113(41), E6281-E6289, 2016. doi:10.1073/pnas.1612392113 
[111] L. P. Wang, F. Li, D. Wang, K. Xie, D. Wang, X. Shen, J. Z. Tsien. NMDA receptors in dopaminergic neurons are crucial for habit learning. Neuron 72(6), 1055-1066, 2011. doi:10.1016/j.neuron.2011.10.019

[112] S. X. Luo, L. Timbang, J. I. Kim, Y. Shang, K. Sandoval, A. A. Tang, J. L. Whistler, J. B. Ding, E. J. Huang. TGF- $\beta$ signaling in dopaminergic neurons regulates dendritic growth, excitatory-inhibitory synaptic balance, and reversal learning. Cell Reports 17(12), 3233-3245, 2016 doi:10.1016/j.celrep.2016.11.068

[113] K. Jastrzębska, M. Walczak, P. E. Cieślak, Ł. Szumiec, M. Turbasa, D. Engblom, T. Błasiak, J. R. Parkitna. Loss of NMDA receptors in dopamine neurons leads to the development of affective disorder-like symptoms in mice. Science Reports 6, 37171, 2016. doi:10.1038/srep37171

[114] L. Deserno, F. Schlagenhauf, A. Heinz. Striatal dopamine, reward, and decision making in schizophrenia. Dialogues in Clinical Neuroscience 18(1), 77-89, 2016.

[115] L. Deserno, Q. J. Huys, R. Boehme, R. Buchert, H. J. Heinze, A. A. Grace, R. J. Dolan, A. Heinz, F. Schlagenhauf. Ventral striatal dopamine reflects behavioral and neural signatures of model-based control during sequential decision making. Proceedings of the National Academy of Sciences of the U. S. A. 112(5), 1595-1600, 2015. doi:10.1073/pnas.1417219112

[116] A. Sinayev,E. Peters. Cognitive reflection vs. calculation in decision making. Frontiers in Psychology, 6, 532, 2015. doi:10.3389/fpsyg.2015.00532

[117] A. Shenhav, M. M. Botvinick, J. D. Cohen. The expected value of control: an integrative theory of anterior cingulate cortex function. Neuron 79(2), 217-240, 2013. doi:10.1016/j.neuron.2013.07.007.

[118] J. Scholl, N. Kolling, N. Nelissen, C. J. Stagg, C. J. Harmer, M. F. Rushworth. Excitation and inhibition in anterior cingulate predict use of past experiences. Elife 6, pii: e20365, 2017. doi:10.7554/eLife.20365

[119] S. R. Heilbronner, B. Y. Hayden. Dorsal anterior cingulate cortex: A bottom-up view. Annual Review of Neuroscience 39, 149-170, 2016.

doi:10.1146/annurev-neuro-070815-013952

[120] M. Roy, D. Shohamy, T. D. Wager. Ventromedial prefrontal-subcortical systems and the generation of affective meaning. Trends in Cognitive Sciences 16(3), 147-156, 2012. doi:10.1016/j.tics.2012.01.005

[121] S. M. Levens, J. T. Larsen, J. Bruss, D. Tranel, A. Bechara, B. A. Mellers. What might have been? The role of the ventromedial prefrontal cortex and lateral orbitofrontal cortex in counterfactual emotions and choice. Neuropsychologia 54, 77-86, 2014. doi:10.1016/j.neuropsychologia.2013.10.026

[122] N. Cooper, D. S. Bassett, E. B. Falk. Coherent activity between brain regions that code for value is linked to the malleability of human behavior. Scientific Reports 7, 43250, 2017. doi:10.1038/srep43250

[123] J. Brown, K. A. Martin, J. Dudman. Behavioral evidence for feedback gain control by the inhibitory microcircuit of the substantia nigra. bioRxivbeta preprint server. Accessible at: http://biorxiv.org/content/early/2016/11/28/090209. doi:10.1101/090209
[124] S. R. Heilbronner, J. Rodriguez-Romaguera, G. J. Quirk, H. J. Groenewegen, S. N. Haber. Circuit-based corticostriatal homologies between rat and primate. Biological Psychiatry 80(7), 509-521, 2016. doi:10.1016/j.biopsych.2016.05.012

[125] H. C. Lückmann, H. I. Jacobs, A. T. Sack. The cross-functional role of frontoparietal regions in cognition: internal attention as the overarching mechanism. Progress in Neurobiology 116, 66-86, 2014. doi:10.1016/j.pneurobio.2014.02.002

[126] M.J.F. Robinson, A.M. Fischer, A. Ahuja, E.N. Lesser and H. Maniates. Roles of "Wanting" and "Liking" in Motivating Behavior: Gambling, Food, and Drug Addictions. In: E. H. Simpson, P. D. Balsam (Eds.). The Behavioral Neuroscience of Motivation: An Overview of Concepts, Measures, and Translational Applications. Current Topics in Behavioral Neuroscience. 2016;27: 105-136. doi:10.1007/7854_2015_402

[127] K. Brans, P. Verduyn. Intensity and duration of negative emotions: comparing the role of appraisals and regulation strategies. PLoS ONE 9, e92410, 2014. doi:10.1371/journal.pone.0092410

[128] S. M. Ng, W. K. Hou. S. M. Ng, W. K. Hou. Contentment duration mediates the associations between anxious attachment style and psychological distress. Frontiers in Psychology, 8, 258, 2017.

http://doi.org/10.3389/fpsyg.2017.00258

[129] D. Cutuli. Cognitive reappraisal and expressive suppression strategies role in the emotion regulation: an overview on their modulatory effects and neural correlates. Frontiers in Systems Neuroscience 8, 175, 2014. doi:10.3389/fnsys.2014.00175

[130] P. Koval, S. Sütterlin, P. Kuppens. Emotional inertia is associated with lower well-being when controlling for differences in emotional context. Frontiers in Psychology 6, 1997, 2016. doi:10.3389/fpsyg.2015.01997

[131] N. B. Kroemer, C. Burrasch, L. Hellrung. To work or not to work: Neural representation of cost and benefit of instrumental action. In: B. Studer and S. Knecht (Eds.). Motivation - Theory, Neurobiology and Applications. Progress in Brain Research 229, 125-157, 2016. doi:10.1016/bs.pbr.2016.06.009

[132] S. P. Becker, D. R. Leopold, G. L. Burns, M. A. Jarrett, J. M. Langberg, S. A. Marshall, K. McBurnett, D. A. Waschbusch, E. G. Willcutt. The internal, external, and diagnostic validity of Sluggish Cognitive Tempo: A meta-analysis and critical review. Journal of the American Academy of Child and Adolescent Psychiatry 55(3), 163-78, 2016. doi:10.1016/j.jaac.2015.12.006

[133] G. R. S. Treviranus. A synopsis of cyclical biaxial (affective) models: from Kraepelin to Askland's genetics and evolutionary neuroanatomy. Poster. 11th International Review Bipolar Disorders, 2010, Rome. International Clinical Psychopharmacology 26, e48, 2011.

doi:10.1097/01.yic.0000405714.06608.40 Online available at https://prezi.com/kosqybvz8aqx/

[134] E. Koutsoukos, E. Angelopoulos. Mood regulation in bipolar disorders viewed through the pendulum dynamics concept. International Journal of Bipolar Disorder 2(1), 9, 2014. doi:10.1186/s40345-014-0009-6 
[135] S. S. Tomkins, R. McCarter. What and where are the primary affects? Some evidence for a theory. Perceptual Motor Skills 18(S1), 119-158, 1964. In: E. V. Demos (Ed.) Exploring affect. The selected writings of Silvan S. Tomkins. Cambridge/Paris: Cambridge UPr/Paris: Maison de l'Homme. 1995.

[136] M. Lenzenweger, R. Depue. A Neurobehavioral Model of Personality Disorders. In D. Cicchetti (Ed.). Developmental Psychopathology: Risk, Disorder, and Adaptation. NY: Wiley-Interscience. 2015.

[137] G. Paolone, C. C. Angelakos, P. J. Meyer, T. E. Robinson, M. Sarter. Cholinergic control over attention in rats prone to attribute incentive salience to reward cues. Journal of Neuroscience. 33(19), 8321-8335, 2013. doi:10.1523/JNEUROSCI.0709-13.2013

[138] M. Krystel-Whittemore, K. N. Dileepan, J. G. Wood. Mast cell: A multi-functional master cell. Frontiers in Immunology 6, 620, 2015. doi:10.3389/fimmu.2015.00620

[139] C. J. Fitzpatrick, S. A. Perrine, F. Ghoddoussi, M. P. Galloway, J. D. Morrow. Sign-trackers have elevated myo-inositol in the nucleus accumbens and ventral hippocampus following Pavlovian conditioned approach. Journal of Neurochemistry 2016 Jan 4. [Epub ahead of print] doi:10.1111/jnc.13524.

[140] S. Hendrix, K. Warnke, F. Siebenhaar, E. M. Peters, R. Nitsch, M. Maurer. The majority of brain mast cells in B10.PL mice is present in the hippocampal formation. Neuroscience Letters 392(3), 174-177, 2006. doi:10.1016/j.neulet.2005.09.029

[141] B. P. Forester, C. T. Finn, Y. A. Berlow, M. Wardrop, P. F. Renshaw, C. M. Moore. Brain lithium, N-acetylaspartate and myo-inositol levels in older adults with bipolar disorder treated with lithium: a lithium-7 and proton magnetic resonance spectroscopy study. Bipolar Disorders 1(6), 691 700, 2008. doi:10.1111/j.1399-5618.2008.00627.x

[142] J. W. Chang, H. Choi, S. L. Cotman, Y. K. Jung. Lithium rescues the impaired autophagy process in CbCln3$(\Delta \mathrm{ex} 7 / 8 / \Delta \mathrm{ex} 7 / 8)$ cerebellar cells and reduces neuronal vulnerability to cell death via IMPase inhibition. Journal of Neurochemistry 116(4), 659-668, 2011. doi:10.1111/j.1471-4159.2010.07158.x

[143] C. J. Fitzpatrick, J. D. Morrow. Subanesthetic ketamine decreases the incentive-motivational value of reward-related cues. Journal of Psychopharmacology 31(1), 67-74, 2017. doi:10.1177/0269881116667709

[144] W. Zhou, N. Wang, C. Yang, X. M. Li, Z. Q. Zhou, J. J. Yang. Ketamine-induced antidepressant effects are associated with AMPA receptors-mediated upregulation of $\mathrm{mTOR}$ and BDNF in rat hippocampus and prefrontal cortex. European Psychiatry 29(7), 419-423, 2014. doi:10.1016/j.eurpsy.2013.10.005

[145] C. L. Lee, Y. H. Jiang, H. C. Kuo. Increased apoptosis and suburothelial inflammation in patients with ketamine-related cystitis: a comparison with non-ulcerative interstitial cystitis and controls. BJU International 112(8), 1156-1162, 2013. https://doi.org/10.1111/bju.12256

[146] T. Fujimoto, T. Nishiyama, K. Hanaoka. Inhibitory effects of intravenous anesthetics on mast cell function. Anesthesia \& Analgesia 101(4), 1054-1059, 2005. doi:10.1213/01.ane.0000166955.97368.80
[147] A. Can, P. Zanos, R. Moaddel, H. J. Kang, K. S. Dossou, I. W. Wainer, J. F. Cheer, D. O. Frost, X. P. Huang, T. D. Gould. Effects of ketamine and ketamine metabolites on evoked striatal dopamine release, dopamine receptors, and monoamine transporters. The Journal of Pharmacology and Experimental Therapeutics 359(1), 159-170, 2016. http://doi.org/10.1124/jpet.116.235838

[148] S. Flagel, T. E. Robinson. Neurobiological basis of individual variation in stimulus-reward learning. Current Opinion in Behavioral Sciences 13, 178-185, 2017. doi:10.1016/j.cobeha.2016.12.004

[149] O. Hikosaka. The habenula: from stress evasion to value-based decision-making. Nature Reviews in Neuroscience, 11(7), 503-513, 2010. doi:10.1038/nrn2866

[150] V. M. Namboodiri, J. Rodriguez-Romaguera, G. D. Stuber. The habenula. Current Biology 26(19), R873-R877, 2016. doi:10.1016/j.cub.2016.08.051

[151] S. Torrisi, C. L. Nord, N. L. Balderston, J. P. Roiser, C. Grillon, M. Ernst. Resting state connectivity of the human habenula at ultra-high field. Neuroimage 147, 872-879, 2017. doi:10.1016/j.neuroimage.2016.10.034

[152] S. K.Peters, K. Dunlop, J. Downar. Cortico-striatal-thalamic loop circuits of the salience network: A central pathway in psychiatric disease and treatment. Frontiers in Systems Neuroscience, 10, 104, 2016. doi:10.3389/fnsys.2016.00104

[153] C. L. Danna, P. D. Shepard, G. I. Elmer. The habenula governs the attribution of incentive salience to reward predictive cues. Frontiers in Human Neuroscience 7, 781, 2013. doi:10.3389/fnhum.2013.00781

[154] J. S. Ide, C. S. Li. Error-related functional connectivity of the habenula in humans. Frontiers in Human Neuroscience 5, 25, 2011. doi:10.3389/fnhum.2011.00025

[155] O. Hikosaka, S. R. Sesack, L. Lecourtier, P. D. Shepard. Habenula: crossroad between the basal ganglia and the limbic system. Journal of Neuroscience 28(46), 11825-11829, 2008. doi:10.1523/JNEUROSCI.3463-08.2008

[156] J. J. Balcita-Pedicino, N. Omelchenko, R. Bell, S. R. Sesack. The inhibitory influence of the lateral habenula on midbrain dopamine cells: ultrastructural evidence for indirect mediation via the rostromedial mesopontine tegmental nucleus. Journal Comparative Neurology. 519(6), 1143-1164, 2011. doi:10.1002/cne.22561

[157] J. S. Wright, J. Panksepp. An evolutionary framework to understand foraging, wanting, and desire: The neuropsychology of the SEEKING system. Neuropsychoanalysis 14(1), $5-75,2012$.

[158] L. W. van Kerkhof, R. Damsteegt, V. Trezza, P. Voorn, L. J. Vanderschuren. Functional integrity of the habenula is necessary for social play behaviour in rats. European Journal of Neuroscience 38(10), 3465-3475, 2013. doi:10.1111/ejn.12353

[159] R. P. Lawson, B. Seymour, E. Loh, A. Lutti, R. J. Dolan, P. Dayan, N. Weiskopf, J. P. Roiser. The habenula encodes negative motivational value associated with primary punishment in humans. Proceedings of the National Academy of Science of the U.S.A. 111(32), 11858-11863, 2014. doi:10.1073/pnas.1323586111 
[160] D. J. Furman, I. H. Gotlib. Habenula responses to potential and actual loss in major depression: preliminary evidence for lateralized dysfunction. Social and Cognitive Affective Neuroscience 11(5), 843-851, 2016.

doi:10.1093/scan/nsw019

[161] M. M. Mirrione, D. Schulz, K. A. Lapidus, S. Zhang, W. Goodman, F. A. Henn. Increased metabolic activity in the septum and habenula during stress is linked to subsequent expression of learned helplessness behavior. Frontiers in Human Neuroscience 8, 29, 2014. doi:10.3389/fnhum.2014.00029

[162] K. Svenningsen, M. T. Venø, K. Henningsen, A. S. Mallien, L. Jensen, T. Christensen, J. Kjems, B. Vollmayr, O. Wiborg. MicroRNA profiling in the medial and lateral habenula of rats exposed to the learned helplessness paradigm: Candidate biomarkers for susceptibility and resilience to inescapable shock. PLoS One. 11(8), e0160318, 2016.

doi:10.1371/journal.pone.0160318

[163] Y. Ootsuka, M. Mohammed. Activation of the habenula complex evokes autonomic physiological responses similar to those associated with emotional stress. Physiological Reports 3(2), pii: e12297, 2015. doi:10.14814/phy2.12297

[164] F. M. Schmidt, S. Schindler, M. Adamidis, M. Strauß, A. Tränkner, R. Trampel, M. Walter, U. Hegerl, R. Turner, S. Geyer, P. Schönknecht. Habenula volume increases with disease severity in unmedicated major depressive disorder as revealed by 7 T MRI. European Archives of Psychiatry and Clinical Neurosciences 267(2), 107-115, 2017. doi:10.1007/s00406-016-0675-8

[165] R. P. Lawson, C. L. Nord, B. Seymour, D. L. Thomas, P. Dayan, S. Pilling, J. P. Roiser. Disrupted habenula function in major depression. Molecular Psychiatry 22(2), 202-208, 2017. doi:10.1038/mp.2016.81

[166] C. Winter, B. Vollmayr, A. Djodari-Irani, J. Klein, A. Sartorius. Pharmacological inhibition of the lateral habenula improves depressive-like behavior in an animal model of treatment resistant depression. Behavioural Brain Research 216(1), 463-465, 2011. doi:10.1016/j.bbr.2010.07.034

[167] F. Cirulli, L. Pistillo, L. de Acetis, E. Alleva, L. Aloe. Increased number of mast cells in the central nervous system of adult male mice following chronic subordination stress. Brain, Behavior, and Immunity 12(2), 123-133, 1998. doi:10.1006/brbi.1998.0505

[168] M. Wilhelm, B. King, A. J. Silverman, R. Silver. Gonadal steroids regulate the number and activational state of mast cells in the medial habenula. Endocrinology 141(3), 1178-1186, 2000. doi: 10.1210/endo.141.3.7352

[169] Y. W, Hsu, S. D. Wang, S. Wang, G. Morton, H. A. Zariwala, H. O. de la Iglesia, E. E. Turner. Role of the dorsal medial habenula in the regulation of voluntary activity, motor function, hedonic state, and primary reinforcement. Journal of Neuroscience 34(34), 11366-11384, 2014. doi:10.1523/JNEUROSCI.1861-14.2014

[170] D. S. Moura, S. Sultan, S. Georgin-Lavialle, N. Pillet, F. Montestruc, P. Gineste, S. Barete, G. Damaj, A. Moussy, O. Lortholary, O. Hermine. Depression in patients with mastocytosis: prevalence, features and effects of masitinib therapy. PLoS One 6(10), e26375, 2011. doi:10.1371/journal.pone.0026375
[171] R. Musil. The man without Qualities. The 1st Vol. of 3: A Sort of Introduction - The Like of It Now Happens (I). New York, N.Y. Perigee Books, 1980. Chapter 62.

[172] K. Jaspers. General Psychopathology. Volume II. Transl. Hoenig J, Hamilton MW. Baltimore: Johns Hopkins Univ Pr, 1997 , p. 547

[173] E. J. Nunes, P. A. Randall, S. Podurgiel, M. Correa, J. D. Salamone. Nucleus accumbens neurotransmission and effortrelated choice behavior in food motivation: effects of drugs acting on dopamine, adenosine, and muscarinic acetylcholine receptors. Neuroscience and Biobehavioral Reviews 37(9 Pt A), 2015-2025, 2013. doi:10.1016/j.neubiorev.2013.04.002

[174] J. D. Salamone, M. Correa, E. J. Nunes, P. A. Randall, M. Pardo. The behavioral pharmacology of effort-related choice behavior: Dopamine, adenosine and beyond. Journal of the Experimental Analysis of Behavior 97(1), 125-146, 2012. doi:10.1901/jeab.2012.97-125

[175] J. D. Salamone, S. E. Yohn, L. López-Cruz, N. San Miguel, M. Correa. Activational and effort-related aspects of motivation: neural mechanisms and implications for psychopathology. Brain 139(Pt5), 1325-1347, 2016. doi:10.1093/brain/aww050

[176] M. P. Paulus, Q. J. Huys, T. V. Maia. Computational Psychiatry: From mechanistic insights to the development of new treatments. Biological Psychiatry: Cognitive Neuroscience and Neuroimaging 1(5), 382 - 385, 2016. doi:10.1016/j.bpsc.2016.08.001

[177] E. Cartoni, B. Balleine, G. Baldassarre. Pavlovian-instrumental transfer: A review. Neuroscience \& Biobehavioral Reviews 71, 829-848, 2016.

doi:10.1016/j.neubiorev.2016.09.020

[178] K. R. Ridderinkhof. Neurocognitive mechanisms of perception-action coordination: a review and theoretical integration. Neuroscience \& Biobehavioral Reviews 46 Pt 1, 3-29, 2014. doi:10.1016/j.neubiorev.2014.05.008

[179] N. K. Hansell, G. S. Halford, G. Andrews, D. H. Shum, S. E. Harris, G. Davies, S. Franic, (...), M. J. Wright. Genetic basis of a cognitive complexity metric. PLoS One 10(4), e0123886, 2015. doi:10.1371/journal.pone.0123886

[180] W. R. Stauffer, A. Lak, S. Kobayashi, W. Schultz. Components and characteristics of the dopamine reward utility signal. Journal of Comparative Neurology 524(8), 1699-1711. doi:10.1002/cne. 23880

[181] F. Zhang, H. C. Tsai, R. D. Airan, G. D. Stuber, A. R. Adamantidis, L. de Lecea, A. Bonci, K. Deisseroth. Optogenetics in Freely Moving Mammals: Dopamine and Reward. Cold Spring Harbor Protocols 2015(8), 715-724, 2015. doi:10.1101/pdb.top086330

[182] A. Kepecs, B. D. Mensh. Emotor control: computations underlying bodily resource allocation, emotions, and confidence. Dialogues in Clinical Neuroscience, 17(4), 391401, 2015

[183] Y. Li, C. Lindemann, M. J. Goddard, B. I. Hyland. Complex multiplexing of reward-cue- and licking-movement-related activity in single midline thalamus neurons. Journal of Neuroscience 36(12), 3567-3578, 2016. doi:10.1523/JNEUROSCI.1107-15.2016

[184] C. Calanchini, C. Bassetti, M. R. Celio. Special edition on positive emotions. Journal of Comparative Neurology 524(8), 
1529-1531, 2016. doi:10.1002/cne.23974 [Papers from the Congress "Brain Circuits of Positive Emotions", 19-23 October 2014, Ascona, Switzerland, 19-23 October 2014 Accessible at: http://www.unifr.ch/anatomy/emotions/.

[185] M. C. Antle, R. Silver. Circadian Insights into Motivated Behavior. In: E. H. Simpson, P. D. Balsam (Eds.). The Behavioral Neuroscience of Motivation: An Overview of Concepts, Measures, and Translational Applications. Current Topics in Behavioral Neuroscience 27, 105-136, 2016. doi:10.1007/7854_2015_384

[186] T. Kawauchi, K. Ishimaru, Y. Nakamura, N. Nakano, M. Hara, H. Ogawa, K. Okumura, S. Shibata, A. Nakao. Clock-dependent temporal regulation of IL-33/ST2-mediated mast cell response. Allergology International pii: S1323-8930(17)30008-4, 2017. doi:10.1016/j.alit.2017.02.004

[187] Y. Nakamura, K. Ishimaru, S. Shibata, A. Nakao. Regulation

i Abbreviation codes:

1. Neuroanatomy, Neurochemistry: ACC Anterior cingulate cortex; aINS Anterior insula; CSTC: Cortico-striato-thalamo-cortical circuits; Nac Nucleus accumbens; OFC Orbitofrontal cortex; vmPFC ventromedial Pre-Frontal Cortex. PVT paraventricular nucleus of thalamus. MC Mast cell; HA Histamine; NMDAR $N$-methyl-D-aspartate receptor for glutamate with e.g. NR2B-subunits; $\mathrm{SNr}$ substantia nigra (basal ganglia).

2. Psychology / Ethology: UOs Uncertainty-Oriented Individuals; COs Certainty-Oriented Individuals (Richard M. Sorrentino); UO-versus-CO Uncertainty versus Certainty "orientation"; GTs goal-trackers; GT goal-tracking; STs sign-trackers; ST sign-tracking.

CS conditioned stimulus; US unconditioned stimulus. MBL Model-based learning; MFL Model-free learning.

3. Neuro-economics: Effme maximal expendable effort; RPE Reward Prediction Error; PE (Effme) RPE normalized to the present discount of previous maximum expendable effort.

4. dyn4-TAM modeling. $d y n 4 T A M$ modified classic mixed bipolar disorder model; $\mathbf{T} \sim, 4 D \mathbf{T}$ symbolic 4-dimensional cognitive processing; $4 D$-Thought symbolic 4-dimensional cognitive processing; $\mathbf{A} \sim, 5+D \mathbf{A}$ intuitive 5- or higher-dimensional cognitive processing; $5+D$-Action intuitive 5 - or higher-dimensional cognitive processing; Mood dichotomic negative or positive valence; $\mathbf{M} \sim$ dichotomic negative or positive valence; $\mathrm{T} / \mathrm{t}, \mathrm{A} / \mathrm{a}, \mathrm{M} / \mathrm{m}$ dichotomic realizations of T, $A$, and $M$ in triples. $\mathbf{P}\{\mathrm{A} \rightarrow \mathrm{T}\}$ Perception, i.e. transitions from 5+-Action to $4 D$-Thought; $\mathbf{I}\{\mathrm{T} \rightarrow \mathrm{A}\}$ Intention, i.e. transitions from 4D-Thought to 5+-Action; $\mathbf{A W}$, AWs Appropriation Wave, Appropriation Waves; SHO Simple Harmonic Oscillator; Worry-T $\sim \mathrm{a} \sim \mathrm{m} \sim$ Worry with much Thought, low Action and Mood. of plasma histamine levels by the mast cell clock and its modulation by stress. Science Reports 39934, 2017. doi:10.1038/srep39934

[188] M. Spencer, L. Yang, A. Adu, B. S. Finlin, B. Zhu, L. R. Shipp, N. Rasouli, C. A. Peterson, P. A. Kern. Pioglitazone treatment reduces adipose tissue inflammation through reduction of mast cell and macrophage number and by improving vascularity. PLoS One 9(7), e102190, 2014. doi:10.1371/journal.pone.0102190

[189] G. Treviranus. Mast cell bio-economies: of barriers, routes, neuronal fates (2017), Frontiers in Molecular Neuroscience, submitted.

[190] J. D. Salamone, S. E. Yohn, L. López-Cruz, N. San Miguel, M. Correa. Activational and effort-related aspects of motivation: neural mechanisms and implications for psychopathology. Brain 139(Pt5), 1325-1347, 2016. doi:10.1093/brain/aww050 